published experimental work; one has to turn many pages before one can see even the name of an enzyme and there are virtually no numerical data given. Dr. Reiner's ideal reader, the ignorant but intelligent man, but one, nevertheless, longing to learn, would find himself bewildered by reality. Putting these criticisms aside, this book is a serious piece of scholarship, and provides a useful introduction to the theory of enzyme kineties.

In contrast to Dr. Reiner's solo performance, the Proceedings of the International Symposium on Enzyme Chemistry, relating to a conference which took place in Tokyo and Kyoto in October 1957, contains contributions from 228 authors. Apart from four special lectures delivered by Profs. Chance ("Cytochromes-their Nature and Function in Living Cells"), Engelhardt ("Enzymology and Mechanochemistry of Tissues and Cells"), Lynen ("Phosphatkreislauf und Pasteur-Effekt") and Tamiya ("The Koji, an Important Source of Enzymes in Japan"), the Proceedings are divided into four sections.

The first section covers the mechanisms of enzymatic group transfer, the second, enzyme systems of hydrogen, oxygen and electron transport, the third, the formation of proteins and enzymes, and the fourth relates to enzymes and industry (interpreted to include pharmacology). Many of the contributions are, in effect, short reviews (2-10 pages) of specialized topics, supplemented with what was in 1957 new experimental material. These articles are, in general, of a high standard and are, in the main, very readable.

The title given to the Conference in no way restricted the range of topies; enzyme chemistry was taken to include any reaction catalysed by enzymes in animals, plants and micro-organisms. Papers dealing with the action of thyroxine on isolated animal mitochondria and the role of chlorophyll in photosynthesis occur in the same section.

The majority of contributions are in English, a few in German and even fewer in French. Almost inevitably some of the papers, from veterans of international conferences, have appeared in substantially the same form before or since.

J. B. Chappeli

\section{CHEMISTRY OF PHOSPHORUS}

\section{Phosphorus and Its Compounds}

By John R. Van Wazer. Vol. 1 : Chemistry. Pp. xiii +954. (New York: Interscience Publishers, Inc. ; London: Interscience Publishers, Ltd., 1958.) $208 s$.

I HIS volume must be unique, for it gives in wide scope and considerable detail an account of the structure, the physical and chemical properties, and the chemical reactions of phosphorus and all its main classes of compounds, both inorganic and organic. It is also outstanding, not only for the wide range of the modern scientific information which is so clearly presented, but also for the historical background of this information : each main topic has a historical introduction, so that, for example, the discussion of the structure of one class of compound may range from a brief review of the theories of a century ago to a more detailed discussion of the most recent evidence supplied by nuclear magnetic resonance spectra.
The first two chapters deal respectively with the nuclear and atomic structure of the phosphorus atom, and with interaction between atoms: the second chapter discusses in detail bond-energies and lengths. dipole moments, polarity of molecules, ionic radii, etc. The following chapters discuss in turn various classes of phosphorus compounds. The detailed information available may be assessed from the 380 pages devoted to phosphoric acid and its compounds, divided into five chapters on condensed phosphates, orthophosphoric acid, chain phosphates, ring and branched phosphates and amorphous phosphates, respectively. This treatment ranges in these five chapters from the physical and chemical properties of phosphate minerals on one flank to those of the nucleic acids on the other. Throughout the book the constant comparison of the properties of the purely inorganic compounds of phosphorus and those of their organic substitution products makes fascinating reading, and may well serve both to widen and to readjust the mental balance with which inorganic and organic chemists have hitherto in their different ways assessed the chemistry of phosphorus.

In the preface, the author makes an eloquent plea that the present division of descriptive chemistry into two parts, organic and inorganic, should now be widened to include a third part, namely, phosphorus chemistry. Many chemists will shrink from this suggestion, but it must be admitted that although phosphorus chemistry contains, on one hand, a num. ber of reactions which can be regarded as normal reactions of inorganic compounds, and on the other hand many reactions typical of organic compounds, there lies in the centre a host of reactions and aspects of behaviour which are peculiar to phosphorus. The same statement might possibly be made of the chemistry of every non-metallic element, but the specific chemistry of phosphorus is, in its range and nature, much greater than that of any other element except carbon. This quality is one of the major factors underlying the vast increase in the academic and technical interest in phosphorus chemistry which has occurred during the past twenty years.

The price of this book may appear high by English standards, but the volume contains an immense amount of information, liberally illustrated by X-ray structure diagrams, phase-rule diagrams, etc., and by a wealth of valuable tabulated material. The final three appendixes list in turn : phosphate minerals (40 pages), giving details of each, based largely on Dana's "System of Mineralogy"; single bond energies and distances with electronegativity differences; and thermodynamic data on the compounds of phosphorus.

The book, however, is emphatically not a mere catalogued compilation of facts. In spite of the size of the book, the author has maintained to the end a critical treatment of the material under discussion, and this treatment, combined with the author's pleasant and lucid style, gives the book a personal flavour which heightens the reader's interest throughout the volume.

The publishers are to be congratulated on the general format and printing of the book, and in particular for printing references at the bottom of pages, where they can be immediately noted by the reader, instead of printing thern in a vast huddle at the end of each chapter.

The book will be appreciated by all types of chemist, inorganic, organic, physical and phosphoric. 